Article

\title{
The Southwest China Flood of July 2018 and Its Causes
}

\author{
Lijuan Wang $1,2,3$, Lin Wang $1,2,4, * \mathbb{C}$, Yuyun Liu ${ }^{1}$, Wei Gu ${ }^{5}$, Peiqiang $X u^{1,2}$ and Wen Chen ${ }^{1,2}$ \\ 1 Center for Monsoon System Research, Institute of Atmospheric Physics, Chinese Academy of Sciences, \\ Beijing 100190, China; wanglj_001@163.com (L.W.); lyy@mail.iap.ac.cn (Y.L.); \\ peiqiang@mail.iap.ac.cn (P.X.); chenw@mail.iap.ac.cn (W.C.) \\ 2 College of Earth and Planetary Sciences, University of Chinese Academy of Sciences, Beijing 100049, China \\ 3 Public Meteorological Service Center, China Meteorological Administration, Beijing 100081, China \\ 4 Joint Center for Global Change Studies, Beijing 100875, China \\ 5 Laboratory for Climate Studies and CMA-NJU Joint Laboratory for Climate Prediction Studies, \\ National Climate Center, China Meteorological Administration, Beijing 100081, China; guwei@cma.gov.cn \\ * Correspondence: wanglin@mail.iap.ac.cn
}

Received: 17 April 2019; Accepted: 1 May 2019; Published: 6 May 2019

\begin{abstract}
Excessive rainfall was observed over Southwest China in July 2018, leading to floods in several major tributaries of the Yangtze River and landslide and debris flow in the neighboring provinces. The rainfall during 7-11 July was unusually heavy and broke the record that can be traced back to 1961. The occurrence of the excessive rain can be attributed to the anomalous convection over the western North Pacific and the presence of a mid-latitude Rossby wave train. On one hand, the convection over the western North Pacific was anomalously strong in July 2018, and it could have excited the negative phase of the Pacific-Japan pattern and led to a northwestward shift of the western Pacific subtropical high. Hence, the water vapor transport toward inland China including Southwest China was enhanced, providing a favorable moisture environment for precipitation. On the other hand, a mid-latitude Rossby wave train was observed to propagate from Northern Europe towards East Asia, which was conducive to anomalous ascending motion over Southwest China via warm advection and differential vorticity advection, creating a favorable dynamical condition for precipitation. As a result, the combination of the two effects mentioned above led to the occurrence of the flood over Southwest China in July 2018.
\end{abstract}

Keywords: El Niño-Southern Oscillation (ENSO); East Asian summer monsoon; rainfall; Pacific-Japan (PJ) pattern

\section{Introduction}

Summer is the primary rainy season for most parts of East Asia. The anomalous summertime rainfall often causes meteorological hazards such as floods and droughts, exerting profound influences on society [1,2]. For example, excessive rainfall was observed over eastern China in the summer of 1998 [3], 2003 [4], and 2007 [5], leading to severe floods, causalities, and economic losses. In the summer of 2018, the country-mean rainfall in China reached $356.4 \mathrm{~mm}$, which is $9.6 \%$ more than the climatology and is the highest level during the past 20 years [6]. The excessive rainfall was mainly observed in Northwest China, North China, Northeast China, Southwest China, and the southeastern coast of China, accompanied by many floods and city waterlogging [6]. From the viewpoint of the summer mean, the characteristics and causes of this unusual rainy season have been analyzed thoroughly with an emphasis on the eastern and northern parts of China [6-8]. In contrast, the causes of excessive rainfall in Southwest China has not been explained. Moreover, it is noteworthy that the 
East Asian summer rainfall shows evident sub-seasonal variations [1]. It means that it is necessary to investigate and understand the anomalous summer rainfall and the resultant hazards from the sub-seasonal timescale. For example, several record-breaking rainfalls were observed in Southwest China surrounding the Sichuan Basin in July of $2018[9,10]$, leading to floods in several major tributaries of the Yangtze River including the Min River, Tuo River, and Jialing River, and landslide and debris flow in parts of Sichuan and Gansu Provinces $[9,10]$. Hence, it is meaningful to understand the causes of the flood in Southwest China from a sub-seasonal perspective.

The East Asian summer monsoon (EASM) controls the summer climate of East Asia, and its anomalous behavior is the direct cause of most of the meteorological hazards in China [1,2]. On one hand, the tropical factors such as the El Niño-Southern Oscillation (ENSO) [11,12] and the anomalous convections over the western North Pacific [13-16] can lead to changes in the intensity and position of the western Pacific subtropical high and alter the EASM's subtropical circulation and water vapor transport [17,18]. On the other hand, the extratropical factors such as the North Atlantic sea surface temperature (SST) [19] and the mid-latitude atmospheric disturbances [20-24] also play a crucial role in the variations of the EASM via modulating the mid- and high-latitude atmospheric circulation. Many extreme rainfalls and the resultant floods are caused by the combined effect of both the tropical and the extratropical factors $[20,22]$. Besides, the interactions between the EASM and the Indian summer monsoon can also alter the summer precipitation over Southwest China [25]. In this study, the characteristics and possible causes of the floods that occurred in Southwest China during July 2018 are analyzed. Section 2 describes the data used in this study. Section 3 describes the observed flood over Southwest China in July 2018, and Section 4 discusses the possible causes. Finally, Section 5 presents the conclusion and discusses some remaining issues.

\section{Data}

The monthly mean, daily mean, and 6-hourly atmospheric reanalysis data were collected from the National Center for Environmental Prediction/National Center for Atmospheric Research (NCEP/NCAR) reanalysis dataset with a horizontal resolution of $2.5^{\circ} \times 2.5^{\circ}$ spanning the period from 1948 to present [26]. The column water vapor fluxes were calculated from the 6-hourly NCEP/NCAR reanalysis dataset and integrated from the surface to $300 \mathrm{hPa}$ [27]. The precipitation data were from the daily temperature and precipitation dataset for China region on $0.5^{\circ} \times 0.5^{\circ}$ grids, which was derived from the observation of 2472 meteorological stations in China (see Figure 1 in [28]). This dataset starts from January 1961 and updates every day almost in real time. The interpolated monthly mean outgoing longwave radiation (OLR) data on $2.5^{\circ} \times 2.5^{\circ}$ grids were used as a proxy for convection. This OLR dataset that spans from 1979 to the present was provided by the National Oceanic and Atmospheric Administration (NOAA) [29]. July 2018 is considered in this study, and all the anomalies are defined as the departures from the long-term means of 1981-2010.

\section{Observed Southwest China Flood in July 2018}

Figure 1a shows the rainfall anomalies in China during July 2018, which displays a northeast-southwest-oriented dipole. Below-normal rainfall was observed in the southern part of Northeast China, most parts of eastern China, and the low-latitude Plateau [30] that is located in the most southwestern part of China. Above-normal rainfall was observed in the northern part of Northeast China, North China, and Southwest China. The maximum positive rainfall anomalies exceeding $5 \mathrm{~mm}_{\text {day }}{ }^{-1}$ were observed in Southwest China surrounding the Sichuan Basin (denoted by the blue parallelogram in Figure 1a and referred to as the Sichuan Basin hereafter). The climatology of rainfall in July is approximately $10 \mathrm{~mm}$ day $^{-1}$ and $5 \mathrm{~mm} \mathrm{day}^{-1}$ in the western and eastern portion of the Sichuan Basin (Figure 1b), respectively, so the rainfall in July 2018 almost doubles the climatology in the eastern Sichuan Basin and is approximately 50\% more than average in the western portion of the Sichuan Basin. 
To delineate the temporal evolution of the rainfall in July 2018, the daily mean rainfall was averaged over the Sichuan Basin (indicated by the blue parallelogram in Figure 1a) where excessive monthly rainfall was observed. The daily rainfall time series suggests that three main rainfall events were observed in the Sichuan Basin in July 2018 (Figure 1c). The first was observed on 2-3 July, the second on 7-11 July, and the third on 15-16 July. Besides, several weak rainfall events were observed after 20 July. The rainfall event on 7-11 July is distinct because it persisted for nearly one week and exceeded the historical daily maximum on 9 and 11 July, respectively (Figure 1c). It is during this period that several waterlogging, landslide, and debris flows were reported in Sichuan and Gansu Provinces $[9,10]$. According to the statistics from Department of Civil Affairs of Sichuan Province [10], 761 houses collapsed, 1679 houses were damaged, and 970,400 people suffered from the floods in Sichuan Province alone during the period 8-12 July. Meanwhile, 46,000 hectares of cropland were flooded, and the direct economic losses exceeded 443.9 million US dollars in Sichuan Province alone [10]. In the following section, we will first explain the overall excessive rainfall in July 2018 and second investigate the possible causes of the strong rainfall during the period of 7-11 July.
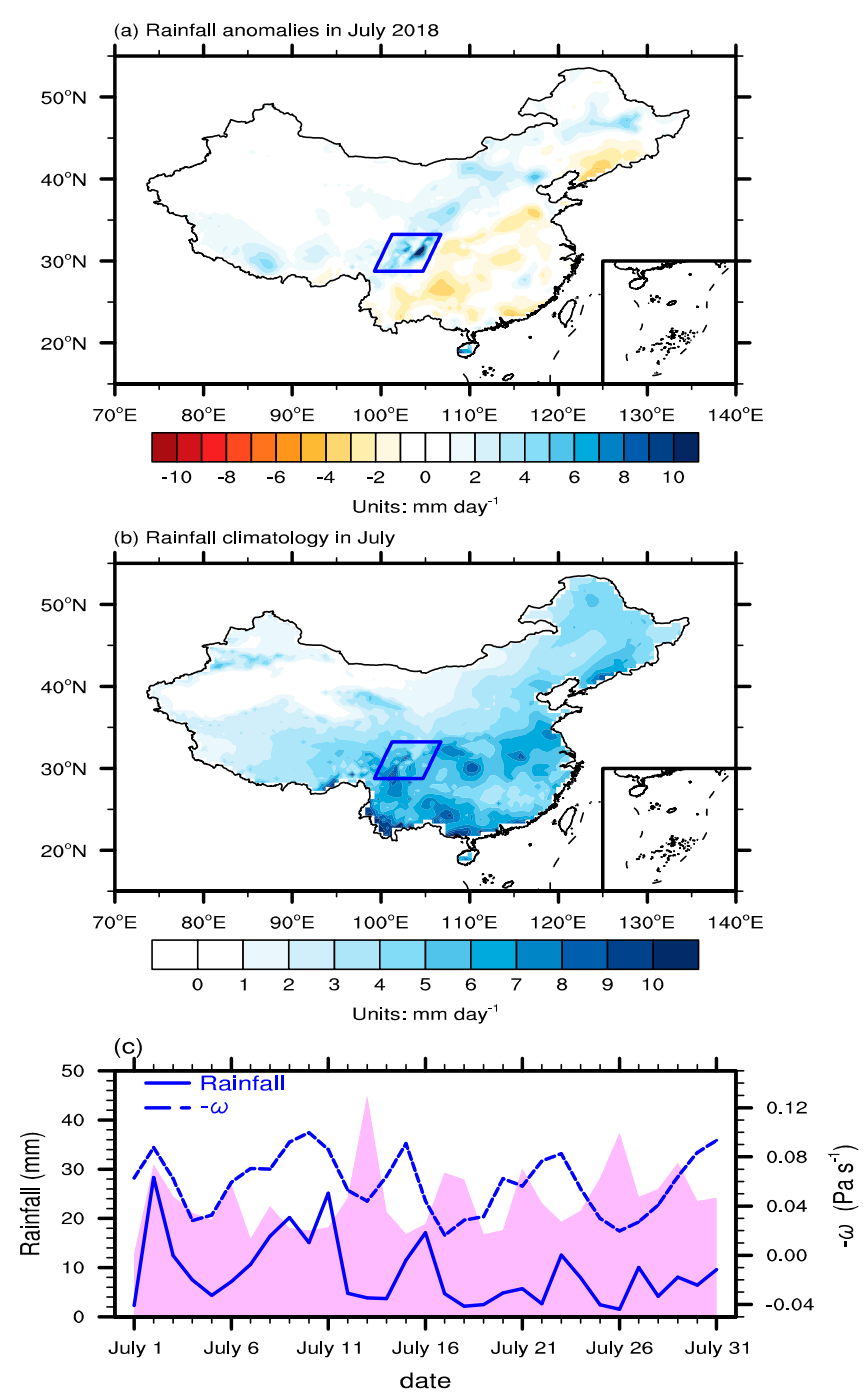

Figure 1. (a) Rainfall anomalies in July 2018 [Shading interval (SI) $=1 \mathrm{~mm} \mathrm{day}^{-1}$ ]; (b) climatology of rainfall in July (SI = $1 \mathrm{~mm} \mathrm{day}^{-1}$ ); (c) time series of daily mean rainfall in July 2018 (blue solid line, unit: $\mathrm{mm}$ ) and daily historical maximum rainfall in July (shading, unit: $\mathrm{mm}$ ) averaged over the Sichuan Basin (the blue parallelogram in Figure 1a or 1b). The blue dashed line in (c) denotes the area averaged $500 \mathrm{hPa}$ vertical velocity (omega, unit: $\mathrm{Pa} \mathrm{s}^{-1}$ ) over regions surrounding the Sichuan Basin, China (see text for details). Note that -1 was multiplied to omega for visual purposes. 


\section{Possible Causes}

\subsection{July Mean}

The status of the regional climate in a particular month largely depends on the atmospheric external forcing and the resultant atmospheric circulation. For the East Asian summer climate, one of the most important atmospheric external forcing is the anomalous convective heating/cooling over the western North Pacific (WNP) [12-14], which could be further linked to the ENSO of the preceding winter [31-33]. Suppressed (enhanced) WNP convection is often observed during the decaying summer of El Niño (La Niña), and it can thereby excite a meridional teleconnection named the Pacific-Japan (PJ) pattern [13] or the East Asia-Pacific (EAP) pattern [14] and lead to changes of precipitation over East Asia [1,2,12].

A La Niña event occurred during the boreal winter of 2017-2018 [27], and it facilitated enhanced convection over the WNP in July 2018 (Figure 2a). As a result, an anomalous lower-tropospheric cyclone was excited to the northwest of the enhanced WNP convection via the Matsuno-Gill-type Rossby wave response (Figure $2 b$ ). The anomalous cyclone dispersed its wave energy northward and formed an anomalous anticyclone near the Sea of Japan (Figure 2b). The resultant meridional dipole resembled the well-defined negative phase of the PJ/EAP pattern, which facilitated a northward movement of the western Pacific subtropical high as confirmed by Figure 2c. The western Pacific subtropical high is normally located at approximately $25^{\circ} \mathrm{N}$ in July in the long-term mean sense with its westernmost point at around $125^{\circ} \mathrm{E}$, but it shifted to approximately $35^{\circ} \mathrm{N}$ in July 2018 with its westernmost point at around $120^{\circ} \mathrm{E}$ (Figure 2c). In the presence of a northwestward-shifted western Pacific subtropical high, the water vapor flux from the ocean could reach inland China further, inducing a zone of water vapor convergence right over the Sichuan Basin (Figure 3a). Meanwhile, strong ascending motion was observed over large areas surrounding the Sichuan Basin (Figure 3b). Hence, both the moisture environment and the dynamical conditions in July 2018 favored the occurrence of heavy rainfall over the Sichuan Basin.

A closer inspection suggests that the moisture convergence over the Sichuan Basin in July 2018 was only slightly stronger than the climatology over the Sichuan Basin (Figure 3c). In contrast, a much stronger-than-normal ascending motion was observed over the large region surrounding the Sichuan Basin in July 2018 (Figure 3d). It suggests that, compared with the moisture environment, the more favorable dynamical condition in July 2018 is likely the key to the occurrence of the excessive heavy rainfall in Sichuan Basin. Previous studies suggested that the incoming Rossby wave train from mid- or high-latitudes is a crucial factor to induce anomalous vertical motion in East Asia [24]. This mechanism is also applicable to July 2018 because a Rossby wave train emanating from Northern Europe was observed to propagate towards East Asia, leading to a wavy structure over Eurasia (Figure 4). The location of the anomalous trough at approximately $90^{\circ} \mathrm{E}$ and ridge at approximately $130^{\circ} \mathrm{E}$ overlapped with those of the trough and ridge in the raw geopotential height field, and the Sichuan Basin was located right to the front of the trough and to the rear of the ridge (Figure 4). In this configuration, enhanced ascending motion over the Sichuan Basin can be induced by warm advection and differential vorticity advection [34]. 
(a) OLR anomalies in July 2018

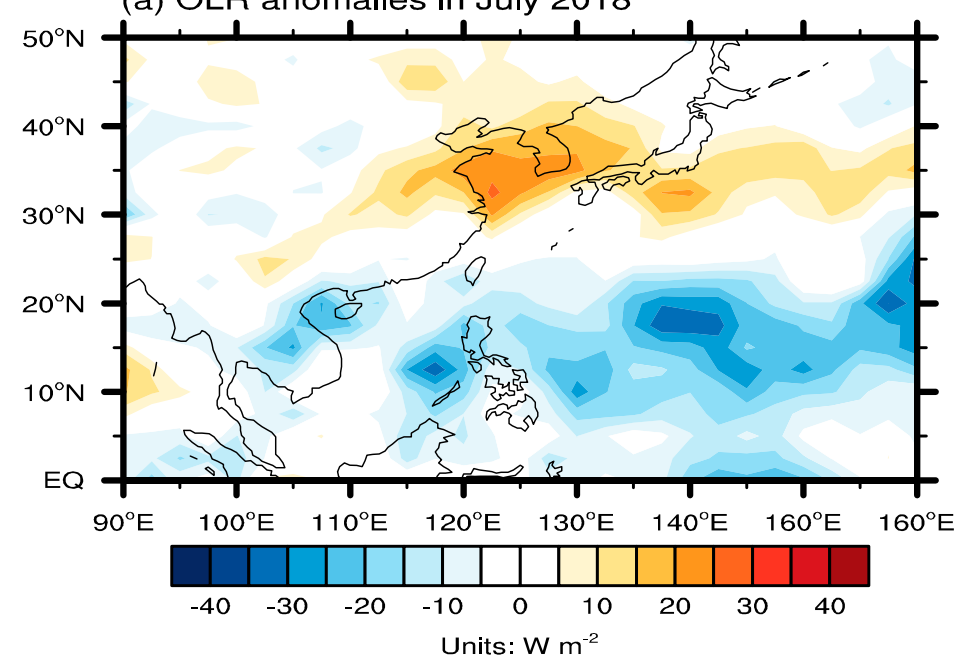

(b) $850 h P a$ wind anomalies in July 2018

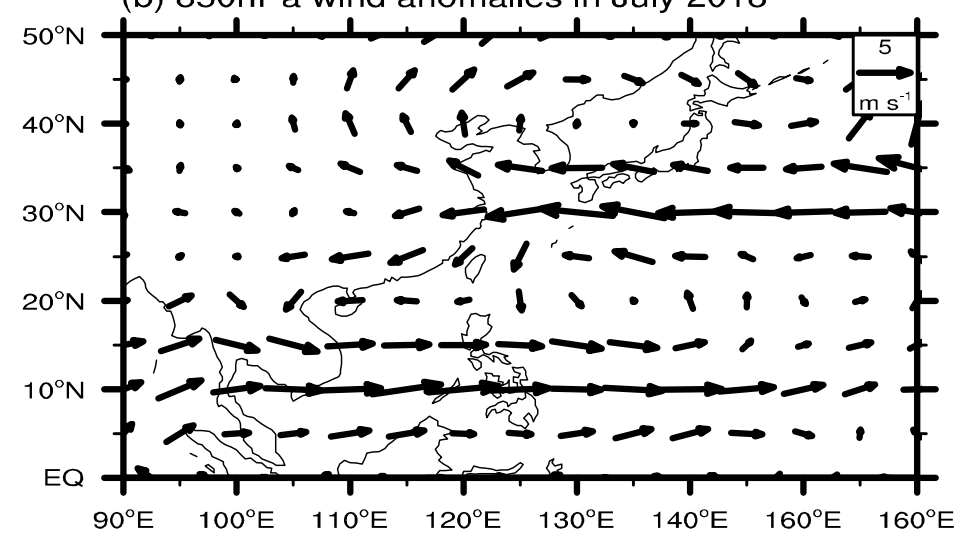

(c) Western Pacific subtropical high in July

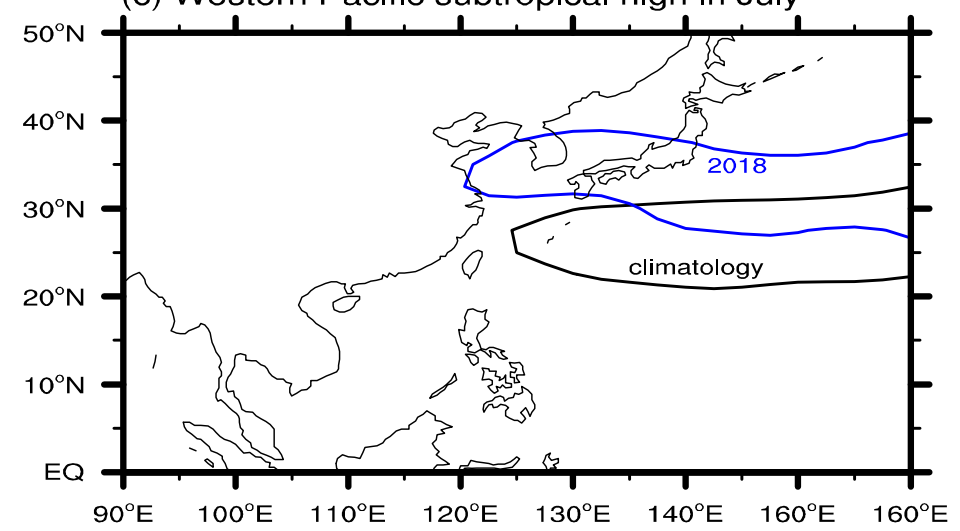

Figure 2. The anomalies of (a) outgoing longwave radiation (OLR; $\mathrm{SI}=5 \mathrm{~W} \mathrm{~m}^{-2}$ ) and (b) $850 \mathrm{hPa}$ winds in July 2018 (unit: $\mathrm{m} \mathrm{s}^{-1}$ ); (c) the location of the western Pacific subtropical high (indicated by the 5880 gpm counter) in July for the climatology (black) and the year 2018 (blue). 

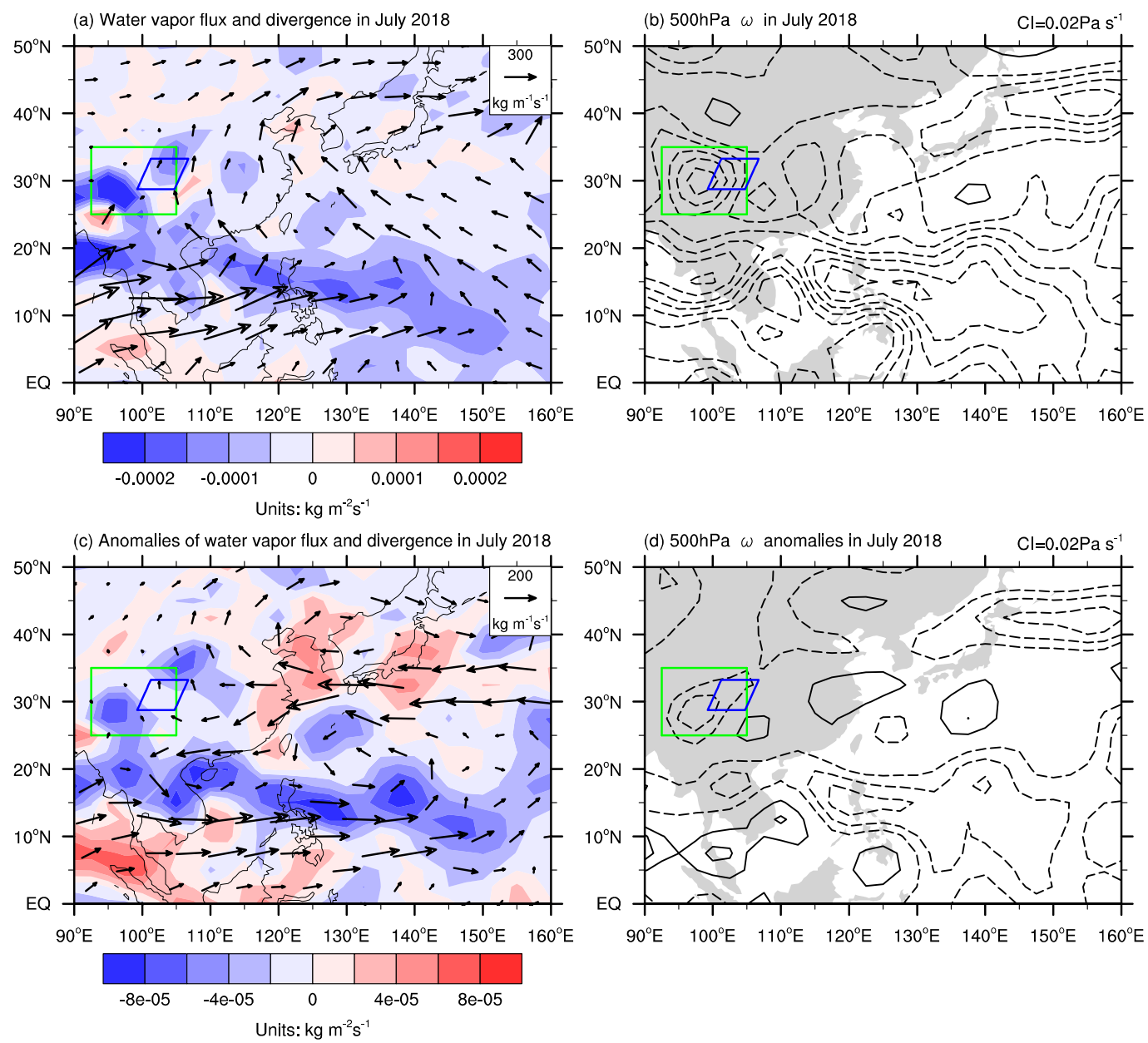

Figure 3. The (a) column-integrated water vapor flux (vector, unit: $\mathrm{kg} \mathrm{m}^{-1} \mathrm{~s}^{-1}$ ) and its divergence (shading, $\mathrm{SI}=5 \times 10^{-4} \mathrm{~kg} \mathrm{~m}^{-2} \mathrm{~s}^{-1}$ ) and (b) the $500 \mathrm{hPa}$ omega [contour interval $(\mathrm{CI})=0.02 \mathrm{~Pa} \mathrm{~s}^{-1}$ ] in July 2018; (c,d) are the same as $(\mathbf{a}, \mathbf{b})$, but for the anomalies in July 2018. The blue parallelograms are the same as those in Figure 1a,b. The green rectangles indicate the region to calculate the omega in Figure 1c.

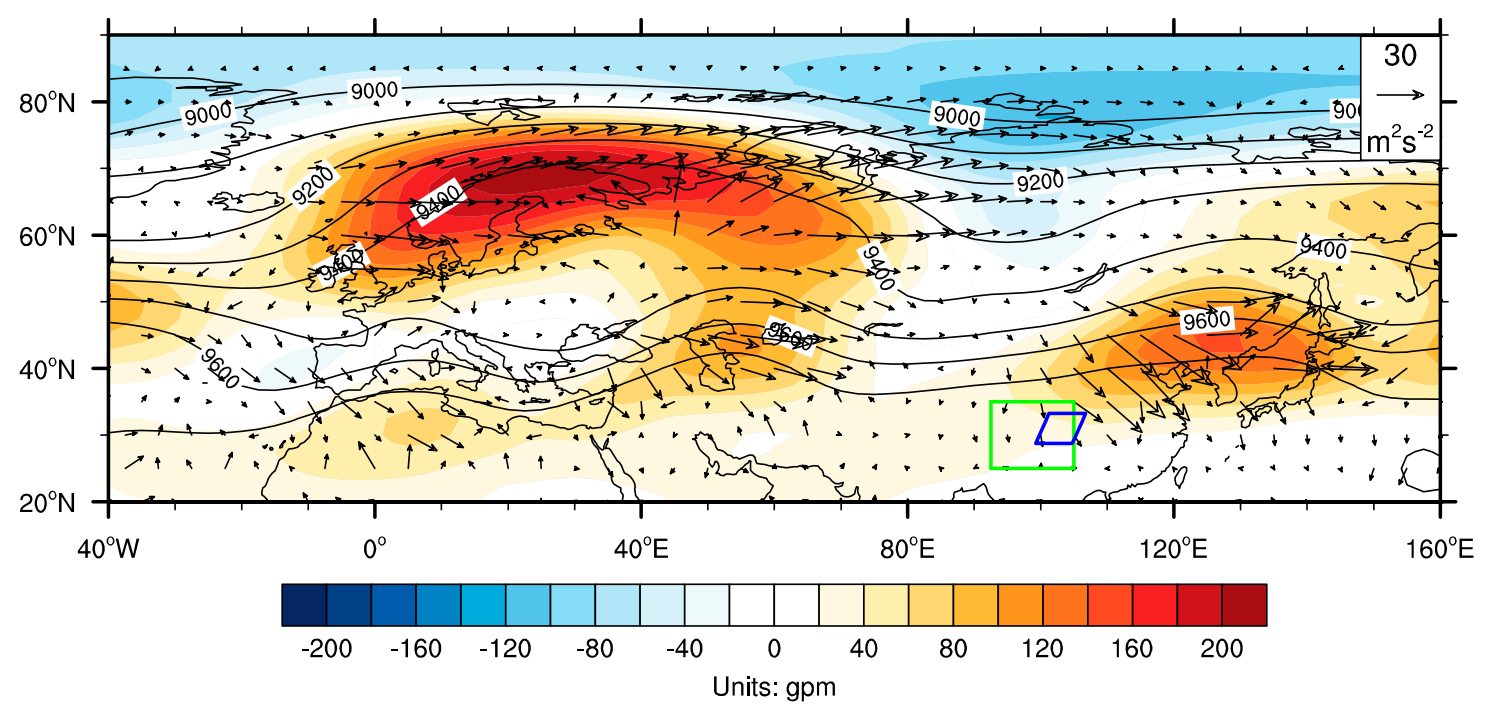

Figure 4. The $300 \mathrm{hPa}$ geopotential height (contour, $\mathrm{CI}=100 \mathrm{gpm}$ ), geopotential height anomalies (shading, SI = $20 \mathrm{gpm}$ ), and the associated wave activity flux [35] (vector, unit: $\mathrm{m}^{2} \mathrm{~s}^{-2}$ ) in July 2018. The blue parallelogram and the green rectangle are the same as those in Figure 3. 


\subsection{Flood During 7-11 July}

Now we turn to address the possible causes of the strong rainfall during the period of 7-11 July. Figure 1c shows the daily time series of the vertical motion over the area surrounding the Sichuan Basin indicated by the green box in Figure 5a. Every rainfall event was accompanied with apparent ascending motion, and the ascending motion during 7-11 July was the strongest. The spatial pattern of the ascending motion during 7-11 July (Figure 5a) and the associated anomalies (Figure 5b) quite resemble their corresponding July-mean counterparts (Figure 3b,d). Again, a Rossby wave train was observed over mid-latitude Eurasia propagating towards East Asia (Figure 6), implying its crucial role in inducing the anomalous ascending motion over the Sichuan Basin (Figure 5b).

(a) $500 \mathrm{hPa} \omega, 7-11$ July 2018

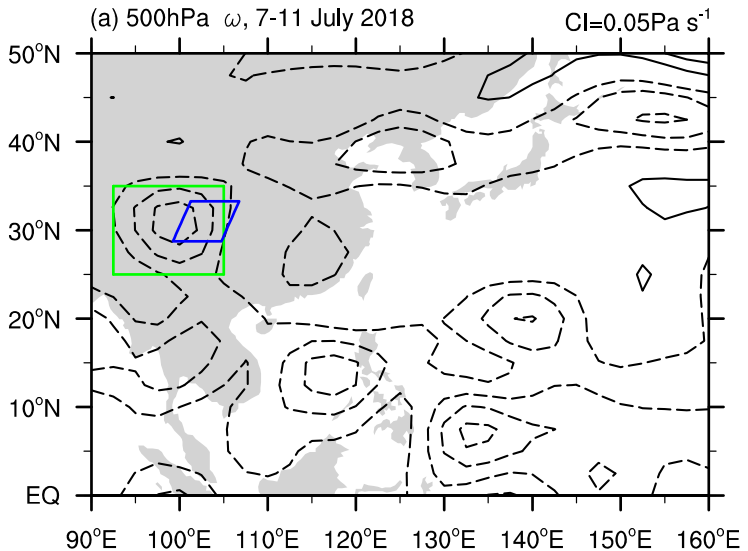

(b) $500 \mathrm{hPa} \omega$ anomalies, $7-11$ July $2018 \quad \mathrm{Cl}=0.05 \mathrm{~Pa} \mathrm{~s}^{-1}$

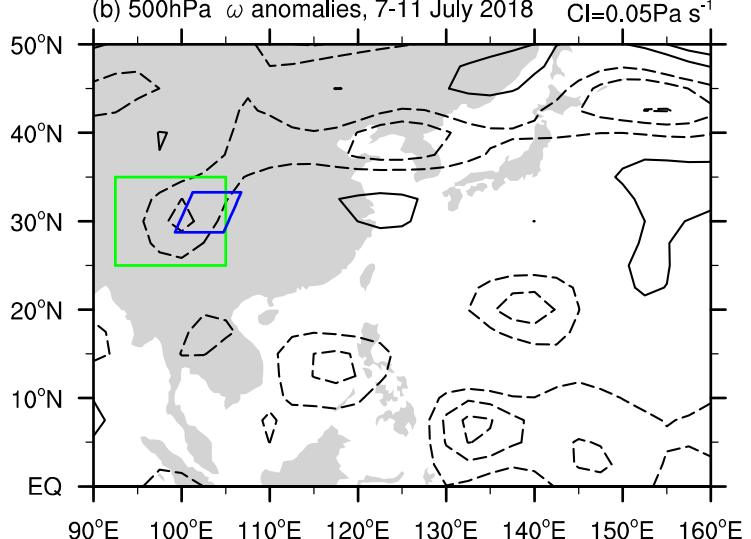

Figure 5. The (a) $500 \mathrm{hPa}$ omega $\left(\mathrm{CI}=0.05 \mathrm{~Pa} \mathrm{~s}^{-1}\right)$ and $(\mathbf{b})$ anomalies of $500 \mathrm{hPa}$ omega $(\mathrm{CI}=0.05 \mathrm{~Pa}$ $\mathrm{s}^{-1}$ ) averaged over 7-11 July 2018. The blue parallelogram and the green rectangle are the same as those in Figure 3.

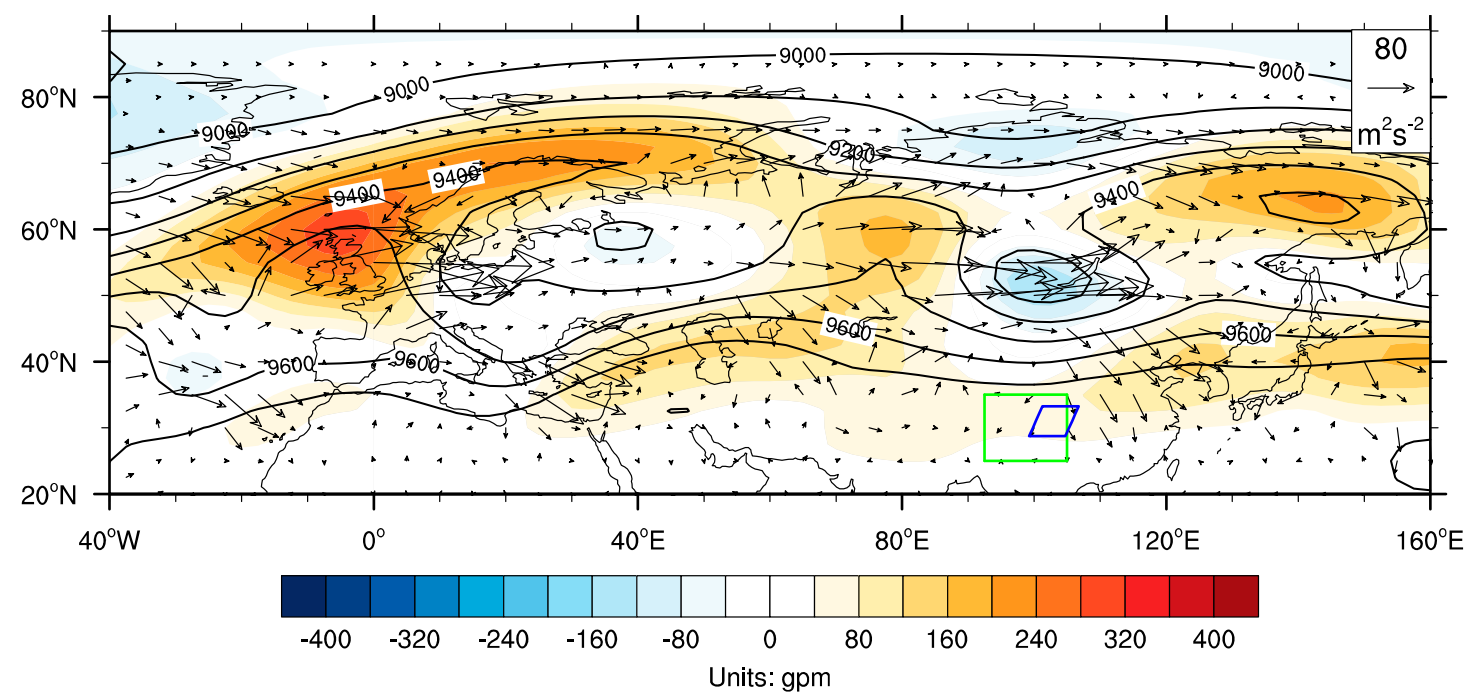

Figure 6. Same as Figure 4, but for the average over 7-11 July 2018.

In order to reveal the processes that led to the anomalous ascending motion in more detail, the linearized quasi-geostrophic omega equation was diagnosed. It is well known that the vertical motion can be induced by the vertical differential vorticity advection, the temperature advection, and the diabatic heating under the quasi-geostrophic approximation [34], which can be described as follows [16,28]: 


$$
\begin{aligned}
\omega \prime & =\left(\nabla^{2}+\frac{f^{2}}{\sigma} \frac{\partial^{2}}{\partial p^{2}}\right)^{-1} \frac{f}{\sigma} \frac{\partial}{\partial p}\left[\overline{\mathbf{V}} \cdot \nabla \zeta^{\prime}+\mathbf{V}_{\prime} \cdot \nabla(f+\bar{\zeta})\right] \\
& +\left(\nabla^{2}+\frac{f^{2}}{\sigma} \frac{\partial^{2}}{\partial p^{2}}\right)^{-1} \frac{R}{\sigma p} \nabla^{2}\left(\overline{\mathbf{V}} \cdot \nabla T_{\prime}+\mathbf{V}_{\prime} \cdot \nabla \bar{T}\right) \\
& -\left(\nabla^{2}+\frac{f^{2}}{\sigma} \frac{\partial^{2}}{\partial p^{2}}\right)^{-1} \frac{R}{\sigma p} \nabla^{2} Q^{\prime} \\
& \equiv \omega^{\prime} \text { dyn }+\omega^{\prime} \text { therm }+\omega^{\prime} Q
\end{aligned}
$$

where overbars indicate long-term mean quantities, and primes indicate the daily anomalies. $f, \mathbf{V}$, $\zeta$, and $Q$ are the Coriolis parameter, the horizontal wind vector, the vertical component of relative vorticity, and the diabatic heating rate estimated as the residual of thermodynamic equation based on 6-hourly NCEP/NCAR reanalysis data, respectively. $\sigma=\frac{R}{p}\left(\frac{R T}{c_{p} p}-\frac{\partial T}{\partial p}\right)$ denotes the static stability of the atmosphere, $R=287 \mathrm{Jg}^{-1} \mathrm{~K}^{-1}$ is the gas constant of dry air, and $c_{p}=1004 \mathrm{JK}^{-1} \mathrm{~kg}^{-1}$ is the specific heat of dry air at constant pressure. The three terms on the right hand side of Equation (1), marked as $\omega^{\prime} d_{y n}, \omega^{\prime}$ therm, and $\omega^{\prime}{ }_{Q}$, represent the anomalies of vertical velocity induced by the differential vorticity advection, the temperature advection, and the diabatic heating, respectively. Here, Equation (1) was solved for each day during the period of 4-13 July 2018 to quantify the contribution of each term on the right hand side to the observed vertical motion anomalies, marked as $\omega{ }^{\prime}$ obs, over the Sichuan Basin. The sum of the three terms on the right hand side of Equation (1) agree well with the observed vertical velocity anomalies although some small discrepancies still exist (not shown), suggesting the effectiveness of the diagnosis.

Figure 7 shows the daily time series of the area-averaged $\omega_{\prime}^{\prime}{ }_{o b s}, \omega_{\prime}^{\prime} d_{y n}, \omega^{\prime}$ therm, and $\omega^{\prime} \mathrm{Q}$ over the area surrounding the Sichuan Basin, i.e., the green box in Figure 5a. On 4 and 5 July, both the ascending motion and the rainfall were weak (Figure 1c), and the anomalous descending motion was observed surrounding the Sichuan Basin (Figure 7). From 6 to 12 July, the stronger-than-normal ascending motion was observed over the Sichuan Basin, leading to the persistent heavy rainfall during 7-11 July (Figure 1c). Diagnosis on the linearized quasi-geostrophic omega equation indicates that the enhanced ascending motion $\left(\omega{ }^{\prime}\right.$ obs $)$ during 6-9 July was mainly caused by $\omega^{\prime}{ }_{Q}$ with additional constructive contribution of $\omega^{\prime} d y n$ from 7 July onward. Despite of the importance of $\omega^{\prime} Q$ during 6-9 July, it is interesting to note that anomalous ascending motion induced by the temperature advection $\left(\omega{ }^{\prime}\right.$ therm $)$ preceded the switch of $\omega^{\prime}{ }_{o b s}$ and $\omega^{\prime}$, from descending to ascending on 5 and 6 July, and that the enhanced ascending motion induced by the temperature advection $\left(\omega_{\prime}^{\prime}\right.$ therm $)$ was stronger than that induced by the diabatic heating $\left(\omega_{Q}^{\prime}\right)$. This result suggests that there was very likely local positive feedback during 5-7 July to cause the anomalous strong ascending motion over the Sichuan Basin. That is, the warm advection could induce some initial ascending anomalies (Figure 7) and weak rainfall (Figure 1c) over the Sichuan Basin on 5 and 6 July. The resultant latent heat releases could warm the atmosphere and further enhance the local ascending motion (Figure 7) and precipitation (Figure 1c). The effect of rainfall-induced latent heat release was weaker than that of warm advection at the initial stage (e.g., 6 July), but it overwhelmed the latter subsequently. These processes could form self-maintained positive feedback between precipitation and ascending motion and explain the occurrence of the strong ascending motion over the Sichuan Basin at the early stage of the heavy rainfall, similar to that discussed in the first rainy season over South China [28]. At the middle and later stages of the heavy rainfall (e.g., 8-11 July), the magnitude and polarity of $\omega^{\prime}{ }_{Q}$ remained similar, but the temperature advection and differential vorticity advection associated with the incoming Rossby wave train (Figure 6) helped to maintain and amplify the ascending motion as shown by $\omega^{\prime}{ }_{d y n}, \omega^{\prime}$ therm (Figure 7). As a result, the persistent and strong ascending motion was observed during 7-11 July, leading to the excessive heavy rainfall over the Sichuan Basin. 


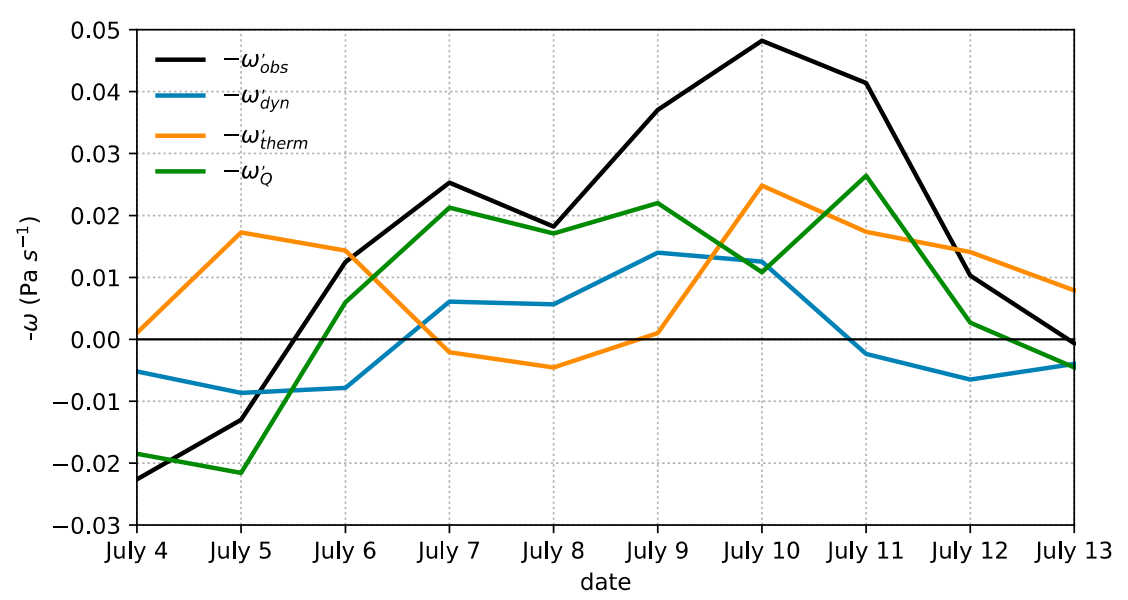

Figure 7. Time series of the observed $500 \mathrm{hPa}$ omega anomalies ( $\omega_{\prime}^{\prime}{ }_{\text {obs }}$, black line), the $500 \mathrm{hPa}$ omega anomalies induced by the differential vorticity advection ( $\omega^{\prime}{ }_{d y n}$, blue line), the temperature advection ( $\omega^{\prime}$ therm, orange line), and the diabatic heating $\left(\omega^{\prime} Q\right.$, green line) averaged over the region surrounding the Sichuan Basin (green rectangle in Figure 5) during the period 4-13 July 2018. Note that -1 was multiplied to omega anomalies for visual purposes.

\section{Conclusions}

Based on gridded precipitation data from China Meteorological Administration, atmospheric data from the NCEP/NCAR reanalysis dataset, and OLR data from NOAA, this study investigated the characteristics of the flood that occurred over Southwest China in July 2018 and its possible causes. It reveals that the rainfall in July 2018 was above average in the northern part of Northeast China, North China, and Southwest China and below average in other parts of eastern China (Figure 1a). Notably, the monthly mean rainfall was almost twice as much as the long-term mean value in a large area of Southwest China surrounding the Sichuan Basin. Inspection on the temporal evolution suggests that the Sichuan Basin experienced three main rainfall events in July 2018. The persistent rainfall event that occurred on 7-11 July broke the record that can be traced back to 1961 (Figure 1c), leading to floods in several major tributaries of the Yangtze River and landslide and debris flow in Sichuan and Gansu Provinces.

The anomalous rainfall pattern in July 2018 was closely related to the enhanced convection over the WNP (Figure 2a), which followed the decaying phase of the preceding La Niña in the 2017-2018 winter. The enhanced WNP convection could have excited the negative phase of the PJ/EAP pattern (Figure 2b) and led to a northwestward shift of the western Pacific subtropical high (Figure 2c). As a result, more water vapor was transported to inland China (Figure $3 a, c)$, providing a favorable moisture environment for the enhanced rainfall over Southwest China, North China, and the northern part of Northeast China. Meanwhile, a Rossby wave train was observed to propagate from Northern Europe towards East Asia, leading to a wavy structure over Eurasia with Southwest China being located right to the front of the trough and to the rear of the ridge (Figure 4). Hence, strong ascending motion (Figure $3 \mathrm{~b}, \mathrm{~d}$ ) could be induced by warm advection and differential vorticity advection associated with the incoming Rossby wave train, providing a favorable dynamical condition for the enhanced rainfall over Southwest China. A closer inspection on the persistent record-breaking heavy rainfall during 7-11 July confirms the crucial role of the Eurasian Rossby wave train in inducing the ascending motion through warm advection and differential vorticity advection (Figures 6 and 7). Moreover, local positive feedback between precipitation and ascending motion was observed during the initial stage of the heavy rainfall.

Considering the role of the mid-latitude Rossby wave train in the formation of the heavy rainfall, it is important to trace its origin. The wave train is often related to the collapse of blocking, as reported in many previous studies [21,22], and this is also the case for the current analysis where blocking activity (Figure 5 in [6]) and blocking-like circulation (Figure 6) were observed over Northern Europe. 
Nevertheless, the predictability of the Rossby wave train is somewhat low due to the chaotic nature of the atmosphere. In addition to the mid-latitude wave train, the topography over Southwest China may also be an important factor for the occurrence of the heavy rainfall [36], and this effect needs to be examined with numerical models in the future.

Author Contributions: L.W. (Lin Wang) designed the research, L.W. (Lijuang Wang) and Y.L. performed the analyses, W.G. collected data, L.W. (Lin Wang) and L.W. (Lijuan Wang) wrote the paper, P.X. and W.C. helped to interpret the results. All authors revised the paper.

Funding: This work was supported by the National Key Research and Development Program of China (2018YFC1506003), the National Natural Science Foundation of China (41721004), the Science Fund of Yunnan Province (2018FY001-18), and the Fundamental Research Funds for the Central Universities.

Acknowledgments: We thank the three anonymous reviewers for their careful review and insightful comments that lead to an improvement of the study.

Conflicts of Interest: The authors declare no conflict of interest.

\section{References}

1. Ding, Y.H.; Chan, J.C.L. The East Asian summer monsoon: An overview. Meteor. Atmos. Phys. 2005, 89, 117-142.

2. Huang, R.H.; Chen, J.L.; Wang, L.; Lin, Z.D. Characteristics, processes, and causes of the spatio-temporal variabilities of the East Asian monsoon system. Adv. Atmos. Sci. 2012, 29, 910-942. [CrossRef]

3. Ding, Y.H.; Hu, G.Q. A study on water vapor budget over China during the 1998 severe flood periods. Acta Meteor. Sinica 2003, 61, 129-145. (in Chinese).

4. Jiao, M.Y.; Yao, X.X.; Zhou, B.; Yang, K.M. An Analysis on Cause of Formation of Huaihe River Basin Flood in 2003; China Meteorological Press: Beijing, China, 2004; p. 212.

5. Cen, S.X.; Gong, Y.F.; Wang, X. The relationship between the atmospheric low-frequency oscillation over Asia and the flood in the Huaihe River valley in the summer of 2007. Chin. J. Atmos. Sci. 2009, 33, 1286-1296.

6. Gu, W.; Chen, L.J. Characteristics of atmospheric and oceanic condition and their influences on summer climate of China in 2018. Meteor. Mon. 2019, 45, 126-134.

7. Chen, L.J.; Gu, W.; Gong, Z.S.; Ren, H.L. Precursory signals of the 2018 summer climate in China and evaluation of the real-time prediction. Meteor. Mon. 2019, 45, 548-559.

8. Chen, L.J.; Gu, W.; Li, W.J. Characteristics of the strong East Asian summer monsoon in 2018 and mechanisms behind. J. Meteor. Res. 2019. [CrossRef]

9. Zhong, H.L.; Gao, G. China climate impact assessment. National Climate Center, China Meteorological Administration. 17 July 2018. Available online: https://cmdp.ncc-cma.net/upload/upload2/yxpj/qhpj_ m180700.doc (accessed on 16 April 2019).

10. Sichuan Provincial Meteorological Bureau. Forecast and service of the heavy rainfall during 8-12 July 2018 in Sichuan Provincial Meteorological Bureau: A summary.

11. Huang, R.H.; Wu, Y.F. The influence of ENSO on the summer climate change in China and its mechanism. Adv. Atmos. Sci. 1989, 6, 21-32.

12. Kosaka, Y.; Xie, S.P.; Lau, N.C.; Vecchi, G.A. Origin of seasonal predictability for summer climate over the Northwestern Pacific. P. Natl. Acad. Sci. 2013, 110, 7574-7579. [CrossRef]

13. Nitta, T. Convective activities in the tropical western Pacific and their impact on the Northern-hemisphere summer circulation. J. Meteor. Soc. Jpn. 1987, 65, 373-390. [CrossRef]

14. Huang, R.H.; Li, W.J. Influence of the heat source anomaly over the western tropical Pacific on the subtropical high over East Asia. In Proceedings of the International Conference on the General Circulation of East Asia, Chengdu, China, 10-15 April 1987; pp. 40-51.

15. Yang, R.W.; Tao, Y.; Cao, J. A mechanism for the interannual variation of the early summer East Asia-Pacific teleconnection wave train. Acta Meteor. Sinica 2010, 24, 452-458.

16. Xu, P.Q.; Wang, L.; Chen, W.; Feng, J.; Liu, Y.Y. Structural changes in the Pacific-Japan pattern in the late 1990s. J. Clim. 2019, 32, 607-621. [CrossRef]

17. Yang, R.W.; Xie, Z.A.; Cao, J. A dynamic index for the westward ridge point variability of the western Pacific subtropical high during summer. J. Clim. 2017, 30, 3325-3341. [CrossRef] 
18. Yang, R.W.; Gui, S.; Cao, J. Bay of Bengal-East Asia-Pacific teleconnection in Boreal summer. J. Geophys. Res. Atmos. 2019, 124. [CrossRef]

19. Gu, W.; Li, C.Y.; Wang, X.; Zhou, W.; Li, W.J. Linkage between mei-yu precipitation and North Atlantic SST on the decadal timescale. Adv. Atmos. Sci. 2009, 26, 101-108. [CrossRef]

20. Li, F.; Lin, J.; He, L.F. The abnormal activity of the westerlies system and its impacts on 2003 summer heavy rainfall over Huaihe basins. J. Appl. Meteor. Sci. 2006, 17, 303-309.

21. Zhang, Q.Y.; Tao, S.Y. Influence of Asian mid-high latitude circulation on East Asian summer rainfall. Acta Meteor. Sinica 1998, 56, 199-211.

22. Wang, L.; Gu, W. The Eastern China flood of June 2015 and its causes. Sci. Bull. 2016, 61, 178-184. [CrossRef]

23. Kosaka, Y.; Chowdary, J.S.; Xie, S.P.; Min, Y.M.; Lee, J.Y. Limitations of seasonal predictability for summer climate over East Asia and the Northwestern Pacific. J. Clim. 2012, 25, 7574-7589. [CrossRef]

24. Xu, P.Q.; Wang, L.; Chen, W. The British-Baikal Corridor: A teleconnection pattern along the summertime polar front jet over Eurasia. J. Clim. 2019, 32, 877-896. [CrossRef]

25. Yang, R.W.; Wang, J. Interannual variability of the seesaw mode of the interface between the Indian and East Asian summer monsoons. Clim. Dyn. 2019. [CrossRef]

26. Kalnay, E.; Kanamitsu, M.; Kistler, R.; Collins, W.; Deaven, D.; Gandin, L.; Iredell, M.; Saha, S.; White, G.; Woollen, J.; et al. The NCEP/NCAR 40-year reanalysis project. Bull. Amer. Meteor. Soc. 1996, 77, 437-471. [CrossRef]

27. Wang, L.J.; Wang, L.; Liu, Y.Y.; Chen, W. The 2017-2018 winter drought in North China and its causes. Atmosphere 2019, 10, 60. [CrossRef]

28. Gu, W.; Wang, L.; Hu, Z.Z.; Hu, K.M.; Li, Y. Interannual variations of the first rainy season precipitation over South China. J. Clim. 2018, 31, 623-640. [CrossRef]

29. Liebmann, B.; Smith, C.A. Description of a complete (interpolated) outgoing longwave radiation dataset. Bull. Amer. Meteor. Soc. 1996, 77, 1275-1277.

30. Cao, J.; Yao, P.; Wang, L.; Liu, K. Summer rainfall variability in low-latitude highlands of China and subtropical Indian ocean dipole. J. Clim. 2014, 27, 880-892. [CrossRef]

31. Zhang, R.H.; Min, Q.Y.; Su, J.Z. Impact of El Niño on atmospheric circulations over East Asia and rainfall in China: Role of the anomalous western North Pacific anticyclone. Sci. China Earth Sci. 2017, 60, 1124-1132. [CrossRef]

32. Xie, S.P.; Kosaka, Y.; Du, Y.; Hu, K.M.; Chowdary, J.; Huang, G. Indo-Western Pacific Ocean capacitor and coherent climate anomalies in post-ENSO summer: A review. Adv. Atmos. Sci. 2016, 33, 411-432. [CrossRef]

33. Li, T.; Wang, B.; Wu, B.; Zhou, T.J.; Chang, C.P.; Zhang, R.H. Theories on formation of an anomalous anticyclone in western north Pacific during El Niño: A review. J. Meteor. Res. 2017, 31, 987-1006. [CrossRef]

34. Holton, J.R. An Introduction to Dynamic Meteorology; 4th Edition; Academic Press: San Diego, CA, USA, 2004; p. 535.

35. Takaya, K.; Nakamura, H. A formulation of a phase-independent wave-activity flux for stationary and migratory quasigeostrophic eddies on a zonally varying basic flow. J. Atmos. Sci. 2001, 58, 608-627. [CrossRef]

36. Hu, K.M.; Xie, S.P.; Huang, G. Orographically anchored El Niño effect on summer rainfall in Central China. J. Clim. 2017, 30, 10037-10045. [CrossRef]

(C) 2019 by the authors. Licensee MDPI, Basel, Switzerland. This article is an open access article distributed under the terms and conditions of the Creative Commons Attribution (CC BY) license (http://creativecommons.org/licenses/by/4.0/). 